\title{
城市建成环境对生物多样性的影响要素与优化路径
}

\section{Built Environment Factors Affecting Urban Biodiversity and Planning Optimization Approaches}

摘要: 城市生物多样性是评价城市生态系统服务功能的重要指标, 对维护城市 系统生态安全和生态平衡、改善城市人居环境具有重要意义。当前中国生态城 市建设较多关注交通、能源、建筑等维度的绿色人工环境塑造, 而较少涉及城 市生物生境系统的营造和修复。本文从城市空间规划设计的视角, 通过相关文 献的梳理, 分析城市建成环境对生物多样性的影响表征, 归纳影响城市生物多 样性的城市建成环境要素, 剖析各类建成环境要素的影响机制, 提出提升城市 生物多样性需要从“提高生物基层质量”和“减缓人工环境干扰” 两维度优化 建成环境的路径, 从生态用地、植被格局、开发强度、人类活动等四个方面阐 述了关键优化指标, 为通过城市空间规划设计保护和提升城市生物多样性提供 依据。

Abstract: Urban biodiversity is a key indicator to assess urban ecosystem services, which is of great significance to maintain ecological security and balance of urban system as well as to improve the urban settlement. The current eco-city development in China is centered by the human-oriented built environment focusing on low carbon transportation, energy saving and green building, while fewer researches and practices have been carried out in the field of urban biological habitat system and its relationship with built environment. From the perspective of urban spatial planning and design, this paper reviews relevant literatures on the relationship between urban built environment and urban biodiversity, analyzes the characteristics of urban flora and fauna, summarizes biological substrate elements and artificial interference elements as two dimensions of built environment factors affecting urban biodiversity and their influencing mechanisms. In order to improve the biological substrate quality as well as to mitigate the disturbance by manmade environment, four aspects of key built environment optimization indicators are elaborated: ecological land, vegetation, building intensity and human activities, with a view to provide basis for planning and design to conserve and enhance urban biodiversity.

关键词: 城市建成环境; 城市生物多样性; 影响要素; 优化路径

Keywords: Urban Built Environment; Urban Biodiversity; Affecting Factors; Optimization Approaches

国家自然科学基金青年基金项目（51408426），同济大学高密度人居环境生态与节 能教育部重点实验室自主科研项目，上海市科学技术委员会 2017 年度 “科技创新 行动计划” 课题 (17DZ1203200)

作者: 干郬, 博士, 同济大学建筑与城市规划学院, 教师, 助理研究员。 jinggan@tongji.edu.cn

\section{1 通过城市规划提升城市生物多样性的必 要性}

\section{1 生物多样性对城市建成环境的支撑作用}

城市生物多样性是在城市范围内各种非人生物 体有规律地结合在一起所体现出来的基因、物种和 城市生态系统的分异程度 ${ }^{[1]}$, 是城市发展的自然本 底以及最重要的城市公共资源之一 ${ }^{[2]}$ 。生物多样性 的变化改变着生态系统过程和生态系统对环境变化 的抵抗力和韧性, 对生态系统服务功能产生深远影 响, 又通过反馈机制影响到人类的健康和福祉 ${ }^{[3]}$ 。 城市生物多样性为地区建成环境提供的生态系统服 务不胜枚举, 而其支撑作用和价值却常常被低估。 除了美学与文化服务价值之外, 城市生态多样性还 可以调节水、空气、土壤的供给和品质, 为提高城 市空气湿度、修复污染土壤、提高土壤肥力和降低 噪声提供服务。城市绿化补氧、固碳, 吸收太阳辐 射, 降低空气污染, 保持水的平衡, 通过遮荫和蒸 散调节城市景观的表面温度, 降低热岛效应。由于 全球进人城市世纪, 城市生物多样性正是大部分人 类能够体验的唯一生物多样性 ${ }^{[4]}$, 公园和自然区域 在支撑城市自然生态亚系统与多种物种栖息生境的 同时，也为居民提供休闲和教育的机会，促使市民 接触自然, 创建场所感, 对人体身心健康产生积极 影响 ${ }^{[5]}$ 。而从经济价值而言, 英国和美国的多项研 究结果显示, 行道树以及可见的自然景观和水体可 以使物业增值 5\% 18\% ${ }^{[6]}$ 。因此, 城市生物多样性 常被作为评价城市生态系统服务功能和城市生态环 境优劣的重要指标, 对维护城市系统生态安全和生 态平衡、改善城市人居环境具有重要意义。 


\section{2 生态城市规划对生物生境系统与建成环境关系研究 的缺失}

自 1971 年联合国教科文组织 (UNESCO) 的 “人与生 物圈” (MBA) 计划开始, 人与自然在城市建成环境中的和 谐共生一直是生态城市研究的热点问题, 城市生物多样性保 护与提升也是生态城市规划的重要组成部分。欧洲和其他一 些国家非常重视城市规划中的生物多样性保护, 在城市规划 的各个阶段将生物多样性列为重要内容, 基于长期监控土地 使用变化对生物多样性的影响, 帮助规划设计人员将生物信 息数据与土地使用数据结合, 并在规划系统中明确提出保护 生物多样性的路径和方法 ${ }^{22}$ 。我国自建设部 2002 年颁布《关 于加强城市生物多样性保护工作的通知》以来, 也逐渐明确 了城市规划对生物多样性保护的重要作用, 尤其在近年来的 生态城市建设中, 与生物多样性相关的城市规划研究日益得 到关注。但总体上看, 我国城市规划领域对生物多样性的研 究与实践尚处于起步阶段, 即便是近年来如火如茶的 “生态 城市”“低碳城市”“低碳生态城市”建设, 也主要聚焦于交通、 能源、建筑等维度的绿色人工环境塑造, 而较少涉及城市生 物生境系统的营造和修复。其中一个主要原因在于规划设计 人员对生物多样性与空间布局之间的关联性缺乏理解, 因此 在生态城市规划前期即使邀请了生物学家进行生物系统调查 和生物空间功能区划研究, 也较难在规划编制和实施过程中 得到有效应用和落实。

笔者认为, 解决上述问题首先需要探讨城市建成环境要 素与城市生物多样性之间的互动关系, 解析相关要素的作用 效应。在本文中, 笔者通过相关文献的梳理, 分析城市建成 环境对生物多样性的影响表征, 明确影响城市生物多样性的 城市建成环境要素, 剖析各类建成环境要素的影响机制, 提 出提升城市生物多样性的建成环境优化路径, 为通过城市空 间规划设计保护和提升城市生物多样性提供依据。

\section{2 城市建成环境对生物多样性的影响表征}

城市建成环境主要由建筑、道路、污染物、噪声、车辆 和人流构成。无序蔓延的城市开发造成许多野生动植物栖息 地日趋萎缩, 直接威胁种群繁衍; 而工业污染和生活垃圾的 无序排放, 改变了生物物种的生理特征及栖息环境, 导致许 多物种灭绝或种群数量大大减少。

城市建成环境对城市生物多样性的影响, 主要体现在城 市动植物特有的生理和群落适应性特征上。城市植物的生理 特征包括 : 覆盖率低; 演替缓慢; 花期相对较长; 抗污染能 力较强。群落特征包括: 广布种、常见种和归化植物比例较 高; 草本植物种类多于木本种类; 杂草和伴人植物占较大比 重; 通常以开花的被子植物为优势种等 ${ }^{[7.9]}$ 。
与受人工种植干预较多的植物相比, 城市动物尤其是野 生动物普遍具有一种 “同步城市化” (Synurbization) 的进化 特征, 即城市中的非家养动物逐步适应人造环境, 甚至其生 存密度在城市环境中比在原生自然条件下更高, 更加如鱼得 水 ${ }^{[10,11]}$, 这在鸟类与小型啮齿类动物中尤为明显 ${ }^{[12,13]}$ 。与自 然状态下的同类相比, 城市动物的生理特征包括: 体型较小, 便于经常性地移动; 杂食性动物比例较高, 饮食可以随时切 换, 部分动物趋向于食用人类提供的食物资源, 如垃圾残渣 等; 能够在人工结构中建造巢穴和栖息, 有相对较长的繁殖 期, 较早的成熟期, 较高的繁殖率和存活率; 能够适应高密 度环境, 有适应于类似原生环境中岩石峡壁的高䇯建筑群的 行为模式; 习惯甚至喜欢人类活动的干扰, 或在行为上适应 人类, 对于非生物条件的巨大变化有生理上的忍受力, 如对 于鸟类而言, 惊飞距离更短; 昼夜活动时间长, 活动范围较 小, 迁徙行为减少等。群落特征则为: 以泛化种 (generalist species) 主导, 一种或几种物种成为城市主要物种; 特化种 (specialist species) 较少, 利用触手可及的食物、庇护所以 及水资源 ; 广布种比例较高。

“同步城市化” 对城市野生动物的空间选择行为模式和 空间分布规律产生了一定的影响。如王彦平等、米库拉等 (Mikula et al.) 研究发现城市中的鸟巢分布存在一定程度的 种间差异, 反映了乌类的城市空间选择适应策略 ${ }^{[14,15]}$ 。雷西 和奥伊勒（Racey \& Euler）对加拿大安大略中部城市哺乳类 的研究 ${ }^{[16]}$, 布莱尔 (Blair) 等对美国加利福尼亚帕洛阿尔 托市 (Palo Alto) 鸟类和蝶类的研究 ${ }^{[17-20]}$, 德尼斯和施密特 (Denys \& Schmidt) 对德国汉堡地区昆虫的研究 ${ }^{[21]}$, 杰曼和 韦克林 (Germaine \& Wakeling) 对美国亚利桑那州图森市蚚 蜴的研究 ${ }^{[22]}$, 梅斯塔斯等 (Maestas et al.) 对美国科罗拉多 流域的鸟类、中型哺乳类的研究 ${ }^{[23]}$, 克鲁克斯等 (Crooks et al.) 对美国加州圣地亚哥鸟类群落的研究 ${ }^{[24]}$, 都展现了鸟类、 昆虫、水生动物等生物存在沿城市化梯度呈现一定空间分布 规律的特征。

\section{3 城市建成环境对生物多样性的影响要素及其影 响机制}

地球上的生物, 都必须依靠太阳、空气、水和土壤等 四项环境因子来存活, 这四大因子是地球生态系统的根本。 其中太阳、空气受人类活动影响较小, 主要属于生物地理 区系的影响; 而水与土壤两个因子则深受人类开发活动的 威胁, 城市建设对水和土壤环境的破坏尤为严重。大多数 学者认为, 在区域尺度, 气候是影响生物群落的主要因素; 在城市尺度, 土地利用、景观格局对生物多样性分布格局 起到决定性作用; 而在中微观尺度, 生境特征、植被结构、 
土地开发和管理强度、土壤等微环境因素可能是决定物种 分布的关键因素 ${ }^{[25]}$ 。

笔者将城市建成环境对生物多样性的影响要素总结为两 个维度：（1）直接承载生物本体的基层承载要素, 即城市 建成环境对土地资源及其结构和环境质量的改变机制要素;

（2）人工环境对自然基质、格局以及生物活动的间接干扰 要素 (图 1)。

\section{1 生物基层承载要素及其影响机制}

生物基层承载要素主要包括承载植物的生态用地基层和 承载动物的植物基层。

\section{1 .1 生态用地}

生态用地指除建设性用地以外, 以提供环境调节和生 物保育等生态服务功能为主要用途、对维持区域生态平衡 和持续发展具有重要作用的土地使用类型, 一般包括绿地、 林地、湿地、耕地、水域等。城市土地使用功能和结构的变化, 造成了生态用地的规模缩减、布局形态改变以及随之带来 的自然景观破碎化, 是导致物种结构和物种丰富度变化的 主要原因 ${ }^{[26]}$ 。

根据保护生态学的“种一面积关系” 理论, 在一定地域 内物种数量与面积之间存在一定的函数关系：通常而言, 当 生境面积越大时, 物种的数量也倾向较多, 越能维持健全的 动植物群落。城市土地利用变化直接导致了自然生态空间规 模的大幅度缩减, 尤其是森林规模和森林覆盖率的降低, 使 得破碎化的栖息地无法满足野生动物种群的最小生存面积。 以鸟类为例, 日本的研究表明, 必须有 $1 \mathrm{~h} \mathrm{~m}^{2}$ 以上植生良好 的绿地才有密林性鸟类出现, $10 \mathrm{hm}^{2}$ 以上植生良好的绿地才 会有较多的森林类鸟类栖息 ${ }^{[27]}$ 。如凯瑟琳 (Kathryn) 认为 局部地区的森林覆盖率、森林用地宽度对栖息地破碎化、鸟 类繁殖与生存能力、植被变化与外来人侵植物等方面有重要 影响 ${ }^{[28]}$ 。阿尔贝蒂等 (Alberti et al.) 在美国普吉特湾的研究 揭示：相较于布局模式，森林规模与鸟类多样性的相关性显 著度更高 ${ }^{[29]}$ 。由此可见, 森林等生态用地的规模效应有利于

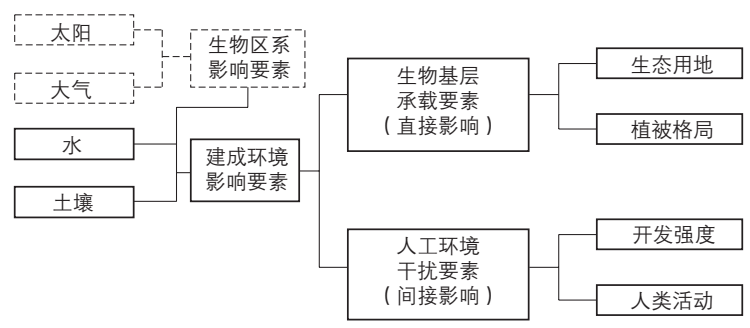

图 1 城市生物多样性的建成环境影响要素 资料来源：作者绘制
满足动植物群落生存繁衍的基本面积要求, 从而形成更为稳 定的种群。

生态用地空间形态结构特征的改变, 通过生境斑块区位、 密度、形状、异质性和连通性等改变了城市地区的生物物理 过程。根据岛屿生态学理论, 城市生境斑块的边缘一般意味 着人类活动的干扰界面, 边缘的界限越长, 越容易受到外来 冲击, 因此形状完整的生境空间较有益于生物多样性。生境 之间的距离越接近, 越方便物种在各种生态位之间移动与交 流, 对植物群落的多样化也越有利, 因此生境之间不能间隔 太远。在城市中, 由于建筑、道路等人工设施的存在, 生境 之间即便在几何空间上趋近, 也可能由于实际空间上的阻隔 而无法进行物质能量交换。因此众多生境间需要有足够宽度 和一定数目的廊道联接, 以促进物种的网状移动与基因交流。 特雷塔罗斯等 (Tratalos et al.) 对英国 15 个城市的研究, 验 证了绿地覆盖率、花园覆盖率、树木在花园和绿地中的覆盖 率、绿地斑块平均面积、花园和绿地斑块平均面积、非封闭 用地斑块平均面积、花园和绿地中树木斑块平均面积等空间 形态指标, 与生物多样性潜力和生态系统服务功能指数之间 的关系 ${ }^{[30]}$ 。赖斯等 (Reis et al.) 采用 20 个和植被、土地覆盖、 土地使用类型相关的变量检验与 8 个街区的鸟类物种丰富度 的相关性, 结论显示具有最大正相关性的变量是地块中的居 住用地比例、原生树木密度、未铺砌路面比例, 而商业地块 密度、外来树木密度以及地块建成面积比例具有最大的负相 关性 ${ }^{[31]}$ 。谢世林等以北京城区 29 个公园为对象, 研究了公 园面积、景观破碎度、林地和人工表面比例、林地最大斑块 指数、景观聚集度指数、景观多样性及均匀度指数等公园景 观格局特征对夏季鸟类群落的影响, 结论发现平均斑块面积 小、公园景观多样性和均匀度指数对鸟类物种丰富度有明显 的不利影响 ${ }^{[32]}$ 。

\section{1 .2 植被格局}

根据自然法则, 所有野生动物的基本需求包括食物、水、 庇护所 ${ }^{[33]}$ 。城市植被可为野生动物提供直接的食物和庇护所: 很多果树和灌木的花芯、果实和种子是野生动物一年四季的 食源。郁闭度较高的乔木, 可以将野生动物与人类干扰安全 隔离。树龄长的高大乔木通常是很多物种的家园, 其内腔可 以成为良好的巢穴之地。水果和浆果中的水分以及植物和草 坪上的晨露或雨后的水滴, 也能成为野生动物的间接水源。 城市植被及其覆盖面积和比例、生物量的改变, 以及不同的 种类结构与配置方式, 会对野生动物受食、筑巢、栖息等行 为的空间生态位产生效应, 继而影响物种数量和分布。

植被覆盖率降低是引起城市生物多样性减少的主要原 因, 对于一个地区的动物来说, 其物种丰富度与植被覆盖率 
呈明显的正相关。李姓学者等 (Lee et al.) 对台湾主要城市 鸟类的研究表明, 鸟类丰富度与植被覆盖指数 (NDVI) 呈 明显的正相关 ${ }^{[34]}$ 。帕克和尼隆 (Parker \& Nilon) 通过对巴 尔的摩 6 个公园灰松鼠的研究, 证明了公园面积、植被盖度 和树阵数量是影响灰松鼠密度最有效的指标 ${ }^{[35]}$ 。乔灌草植被 层, 可以提供不同的食物和庇护基层。葛振鸣等对上海 8 个 园林绿地春季鸟类的研究, 显示植被种数、灌木层盖度、草 本层盖度等因子在影响园林鸟类群落结构和分布中起关键性 作用 ${ }^{[36]}$ 。

通常情况下, 植被越丰富则野生动物的多样性越丰富; 植被越单一, 种群也趋向单一化。肖琨对四川绵阳绿地植物 结构与昆虫多样性关系的研究, 验证了昆虫群落的分布不仅 受植物数量的影响, 同时也受绿地复层结构以及温湿度的影 响 ${ }^{[37]}$ 。晏华等对重庆蝶类的研究显示, 植被种类丰富度越高、 覆盖率越高的生境, 蝴蝶种类和数量越多, 蝴蝶多样性指数 也越高 ${ }^{[38]}$ 。城市中原生植被的减少, 也必然引起野生动物的 栖息环境急剧恶化。布格哈特等 (Burghardt et al.) 对美国宾 州东南部 6 组城郊物业的研究表明, 原生植被主导的物业比 对照组有更多的鳞翅目物种数, 以及更高的鸟类物种丰富度、 生物量和本土繁殖鸟种 ${ }^{[39]}$ 。

野生动物的物种多样性也与植被的空间配置方式有关。 王彦平等对杭州城市行道树带的繁殖鸟类及其鸟巢的研究, 揭示了树冠盖度、至大片林地的距离、至主要水源距离、树 带宽度与特定鸟种鸟巢分布存在正向联系 ${ }^{[14]}$ 。范 - 西奇克 (Van Heezik) 以及奥尔特加 - 阿尔瓦雷扎和麦格雷戈 - 福斯 (Ortega-Alvareza \& MacGregor-Fors) 的研究, 分别指出新西 兰某城和墨西哥城西南部的鸟类丰富度与乔木的平均高度以 及灌木覆盖率、灌木高度、草本植物高度呈正相关 ${ }^{[0,41]}$ 。

\section{2 人工环境干扰要素及其影响机制}

人工环境对生物多样性的干扰主要通过城市土地开发活 动与生物基层竞争各类空间生态位, 以及城市中的高强度人 类活动改变生物本体的生理和群落适应性特征实现。

\section{2 .1 开发强度}

开发强度表征了单位土地的使用程度, 通常包括容积率、 建筑密度、道路网密度、居住密度等。人类开发活动所带来 的生境隔离, 改变了生物生存和繁殖的自然过程, 如花粉传 播受阻和动物穿越行为的阻碍, 会导致基因流动抑制而使近 交和罕见等位基因丢失机会增加, 影响物种的繁殖、生长发 育和种间关系等生物多样性变化过程与趋势 ${ }^{[42]}$ 。如格力斯塔 等 (Glista et al.) 认为交通廊道对生物栖息地的占用导致栖 息地破碎化和岛屿化, 给道路两侧生物穿越带来阻碍甚至造
成野生动物非正常死亡 ${ }^{[43]}$ 。奥尔特加 - 阿尔瓦雷扎和麦格雷 戈－福斯研究了墨西哥城城市化地区绿地、居住用地、商住 混合用地、商业用地与鸟类多样性及其空间分布特征的关系, 发现城市开发程度与鸟类种群结构单一性呈正相关关系 ${ }^{[41]}$ 。 王卿等对上海各区县的研究显示, 人均 GDP、人口密度和 交通网络密度这些人类活动指标, 对生物多样性综合指数和 各类物种的丰富度具有负面影响 ${ }^{[44]}$ 。

\subsection{2 人类活动}

车流量、人流量等人类出行活动以及声环境、光环境、 水环境、大气环境、土壤环境等环境污染和微气候变化, 影 响植物的生物节律和花期以及动物出行、受食、筑巢、通 讯等行为模式, 从而导致生理机能和种群结构的变化。如 胡志军等指出, 道路交通导致动物死亡, 已成为野生脊椎 动物死亡的首要原因 ${ }^{[45]}$ 。阿尔贝蒂和马斯勒夫 (Alberti \& Marzluff) 以及米尔特纳等 (Miltner et al.) 发现城市不透水 地面的增加改变了地表水文状况和微气候环境, 导致了水底 生物的多样性指数以及溪流大型无脊椎动物的生物总量的下 降 ${ }^{[46,47]}$ 。贾森和查尔斯 (Jason \& Charles) 在对加拿大安大 略省伊利湖的灯塔与夜间迁徙鸟死亡原因关系的研究中发 现, 改变光束的强度可以大大减少灯光对鸟类的误导从而降 低其死亡率 ${ }^{[48]}$ 。城市人为活动对于水域的破坏和污染, 如河 流变成暗渠、裁弯取直、水泥衬地、石砌护坡、高筑河堤等, 也会使依赖水域生活的鸟类等物种迅速减少 ${ }^{[49]}$ (表 1)。

\section{表 1 城市环境要素变化对生物的影响}

\begin{tabular}{|c|c|c|}
\hline 城市环境要素及其特征 & 对植物的主要影响 & 对动物的主要影响 \\
\hline $\begin{array}{l}\text { 气候环境 : 温度高, 湿 } \\
\text { 度低, 风速小, 循环弱 }\end{array}$ & $\begin{array}{l}\text { 生长周期更长, 物候 } \\
\text { 期改变 }\end{array}$ & $\begin{array}{l}\text { 繁殖期提前, 部分物种繁 } \\
\text { 殖速度加快, 生物节律被 } \\
\text { 打乱 }\end{array}$ \\
\hline $\begin{array}{l}\text { 土壤环境: 紧实度大, 通 } \\
\text { 透性差, 硬化比例高, 肥 } \\
\text { 力弱, 污染严重 }\end{array}$ & $\begin{array}{l}\text { 群落结构单一, 人侵 } \\
\text { 种比例较高 }\end{array}$ & 改变土壤动物群落结构 \\
\hline $\begin{array}{l}\text { 光环境 : 自然光照少, 人 } \\
\text { 工光照多, 夜间照明干 } \\
\text { 扰, 日间光污染 }\end{array}$ & $\begin{array}{l}\text { 影响植物生物节律和 } \\
\text { 花期 }\end{array}$ & $\begin{array}{l}\text { 改变迁移行为、冬眠行为、 } \\
\text { 繁殖行为以及夜行动物的 } \\
\text { 受食行为, 导致近地面撞 } \\
\text { 击致死 }\end{array}$ \\
\hline 声环境：噪声污染 & 过早调谢 & $\begin{array}{l}\text { 影响鸟类、蝙蝠等主要依 } \\
\text { 赖声音进行通讯的类群的 } \\
\text { 受食能力 }\end{array}$ \\
\hline $\begin{array}{l}\text { 水环境 : 地下水位降低、 } \\
\text { 水污染 }\end{array}$ & $\begin{array}{l}\text { 耐污染水生植物大量 } \\
\text { 繁殖 }\end{array}$ & $\begin{array}{l}\text { 影响鱼类、底栖动物的种 } \\
\text { 类和数量 }\end{array}$ \\
\hline $\begin{array}{l}\text { 大气环境 : 大气污染（粉 } \\
\text { 尘/可吸人颗粒物、二氧 } \\
\text { 化硫、氮氧化合物、一 } \\
\text { 氧化碳等） }\end{array}$ & $\begin{array}{l}\text { 敏感种减少或消失； } \\
\text { 抗污染强的种类保存 }\end{array}$ & $\begin{array}{l}\text { 减缓生物的正常发育, 影 } \\
\text { 响生理机能 }\end{array}$ \\
\hline
\end{tabular}

资料来源：作者整理 


\section{4 提升城市生物多样性的建成环境优化路径}

如上述研究现状与文献梳理所示, 保护和提升城市生物 多样性的建成环境优化路径需要从 “提高基层质量” 和 “减 缓干扰压力”两个维度予以考虑, 涉及生态用地、植被格局、 开发强度和人类活动等四个方面的建成环境要素。宏观尺度 影响生物多样性的城市建成环境要素主要为整体开发强度、 密度、集聚度以及绿地、林地、湿地、耕地、水域等各类生 态用地的规模与结构, 而植被格局数据在宏观尺度上较难获 取。在中微观尺度, 除了延续宏观尺度的具体地块开发强度 要素以外, 绿地和水体作为中心城区小尺度生态用地的载体, 对城市生物多样性有直接影响, 因此在实证研究中, 可以绿 地为主、水体为辅分析其规模和空间形态特征与生物多样性 的关系。另一方面, 为动物提供受食、巢居、休息生态位, 并在小尺度进行测绘和调控植被的规模、结构和种植形态亦 可作为影响生物多样性的建成环境要素进行分析。由于环境 监测数据较难获取, 且该类要素较难在城市空间规划设计中 进行直接调控, 因此在城市规划学科的生物多样性影响研究 中, 环境污染影响要素一般不作为核心研究变量。

基于 “提高基层质量” 和“减缓干扰压力” 两个维度, 本文梳理了提升城市生物多样性的建成环境关键优化指标以 及相应的文献。“提质” 路径主要取决于生境的 “四度”密度、集中度、连通度和高度的提升。论证较为充分的指标 主要在于生境斑块的空间形态特征以及植被的规模与形态,
其中生态用地指标较多聚焦于绿地和林地, 对湿地、水域、 耕地等其他类型生态用地的影响效应和优化路径则需要进一 步梳理。“减扰”路径取决于开发强度的降低和人工一自然 隔离度的增加, 研究论证相对于 “提质” 略显薄弱, 其中对 建筑密度、居住密度、道路网密度的研究较多, 还需要通 过实证研究进一步明晰与城市规划关系更为密切的人口集聚 度、经济开发强度、交通出行等指标的影响效应和优化路径。 “提质” 和 “减扰” 共同作用, 才能更为系统且有效地提升 城市生物多样性（表 2)。

大部分文献以现场调研所获取和计算的生物多样性测度 指标作为因变量, 以潜在影响生物多样性的建成环境变量作 为自变量, 采用统计分析方法, 通过显著性检验, 提取影响 生物多样性的城市建成环境关键影响因子, 优化指标的具体 取值范围也有待在后续的实证研究中进一步探究。

\section{5 结语}

在中国城镇化跨越 50\% 的关键时期, 党的十八大报告 明确提出 “尊重自然、顺应自然、保护自然” 的生态文明 理念, 十八届三中全会提出 “建立系统完整的生态文明制 度体系”, 十九大报告指出 “人与自然是生命共同体”, 并 进一步提出 “构筑尊崇自然、绿色发展的生态体系”, 这些 对新时期的城市规划建设提出了更明确和更高层次的生态转 型要求。联合国人居署和地方政府可持续发展委员会等机构 2012 年联合发布的《城市与生物多样性展望报告》, 指出城

表 2 提升城市生物多样性的建成环境优化路径与优化指标

\begin{tabular}{|c|c|c|c|c|c|c|}
\hline \multirow{2}{*}{\multicolumn{2}{|c|}{$\begin{array}{l}\text { 优化 } \\
\text { 路径 }\end{array}$}} & \multirow{3}{*}{$\begin{array}{c}\begin{array}{c}\text { 优化指标类型 } \\
\text { 正面影响 }\end{array} \\
\text { 用地规模 }\end{array}$} & \multicolumn{2}{|c|}{ 宏观尺度 } & \multicolumn{2}{|c|}{ 中微观尺度 } \\
\hline & & & 负面影响 & 正面影响 & 负面影响 & \\
\hline \multirow{5}{*}{$\begin{array}{l}\text { 提高 } \\
\text { 生物 } \\
\text { 基层 } \\
\text { 质量 }\end{array}$} & \multirow{2}{*}{$\begin{array}{l}\text { 提高 } \\
\text { 生态 } \\
\text { 用地 } \\
\text { 质量 }\end{array}$} & & $\begin{array}{l}\text { 生态用地面积和比例 (绿地、 } \\
\text { 森林为主) }{ }^{[28,29,31]} \text {; 绿地面积 }{ }^{[32]}\end{array}$ & - & - & - \\
\hline & & 空间形态 & $\begin{array}{l}\text { 景观特征指数 }{ }^{[44]} \text {; 生境斑块连 } \\
\text { 通性 }{ }^{[26,32]} \text {; 生态网络连接度 }{ }^{[32]}\end{array}$ & - & - & 生境斑块密度 ${ }^{[30,32]}$; 生境斑块边周比 ${ }^{[30]}$ \\
\hline & \multirow{3}{*}{$\begin{array}{l}\text { 提高 } \\
\text { 植被 } \\
\text { 格局 } \\
\text { 质量 }\end{array}$} & 植被规模 & - & - & $\begin{array}{l}\text { 乔木、灌木、地被层覆盖面积、 } \\
\text { 比例与生物量 }^{[31,34]}\end{array}$ & - \\
\hline & & 植被结构 & - & - & 植被种类 ${ }^{[31,37,38]}$; 本地植被比例 ${ }^{[39]}$ & - \\
\hline & & 植被形态 & - & - & $\begin{array}{l}\text { 树高与树冠盖度 }{ }^{[14]} \text {; 植被空间配 } \\
\text { 置关系 }{ }^{[40,41]}\end{array}$ & - \\
\hline \multirow{5}{*}{$\begin{array}{l}\text { 减缓 } \\
\text { 人工 } \\
\text { 干扰 } \\
\text { 压力 }\end{array}$} & \multirow{3}{*}{$\begin{array}{l}\text { 降低 } \\
\text { 开发 } \\
\text { 强度 }\end{array}$} & 经济发展水平 & - & 经济开发强度 ${ }^{[44]}$ & - & - \\
\hline & & 人口集聚度 & - & 人口密度 ${ }^{[4]}$ & - & - \\
\hline & & 建设开发强度 & - & $\begin{array}{l}\text { 建筑密度 }{ }^{[44]} \text {; 居住密 } \\
\text { 度 }^{[43]} \text {; 道路网密度 }{ }^{[43,44]}\end{array}$ & - & $\begin{array}{l}\text { 建筑密度 }^{[30,41]} \text {; 住户密度 }{ }^{[30]} \text {; 未铺砌 } \\
\text { 路面比例 }\end{array}$ \\
\hline & 减少 & 交通流量 & - & - & - & 车流量、人流量 ${ }^{[14,45]}$ \\
\hline & $\begin{array}{l}\text { 人类 } \\
\text { 活动 }\end{array}$ & 环境污染 & - & - & - & $\begin{array}{l}\text { 气候环境、声环境、光环境、水环境、 } \\
\text { 大气环境、土壤环境等环境污染 }{ }^{[45,48]}\end{array}$ \\
\hline
\end{tabular}


市化对生物多样性和生态系统服务功能而言既是挑战也是机 遇 ${ }^{[50]}$, 也再次为城镇化与城市发展过程中如何保护自然生物 资源, 提供了新的依据和方向。由此可见, 在高密度城市建 成环境中维护和提升生物多样性, 是城市可持续发展面临的 关键问题之一, 导人生物多样性视角也是城市规划尤其是生 态城市规划设计研究中有必要进一步探索的领域, 可为未来 的城市生态转型发展提供更多的借鉴与参考。

目前我国城市规划领域对生物多样性的研究与实践尚 处于起步阶段, 相关理论与实证研究还有待进一步加强。 本文对影响生物多样性的建成环境要素及其影响机制进行 了分类讨论, 生态用地要素主要包括用地规模和空间形态, 植被格局要素主要包括植被规模、结构和形态, 开发强度 要素主要包括经济发展水平、人口集聚度和建设开发强度, 人类活动要素包括交通流量和环境污染程度。本文提出, 提 升城市生物多样性需要从 “提高生物基层质量” 和 “减缓 人工环境干扰” 两个维度同时展开, 并归纳总结了两个维 度四类要素在宏观和中微观两个空间层级的关键优化指标, 指出了可进一步分析的指标类别, 可为开展规划实践和实 证研究提供基础。UP

\section{参考文献}

[1] 俞青青, 包志毅. 城市生物多样性保护规划认识上的若干问题 [J]. 华中 建筑, 2006, 24(6): 90-91.

[2] 徐溯源, 沈清基. 城市生物多样性保护规划理想与实现途径 [J]. 现代城 市研究, 2009(9): 12-18.

[3] 许凯杨, 叶万辉. 生态系统健康与生物多样性 [J]. 生态科学, 2002, 21(3): 279-283.

[4] MÜLLER N, WERNER P. Urban biodiversity and the case for implementing the convention on biological diversity in towns and cities[M] // MÜLLER N, WERNER P. KELCEY J G, eds. Urban biodiversity and design. Oxford: Wiley-Blackwell, 2010: 1-34.

[5] GÓMEZ-BAGGETHUN E, GREN Å, BARTON D N, et al. Urban ecosystem services[M] // FRAGKIAS M, GOODNESS J, GÜNERALP B, et al, eds. Urbanization, biodiversity and ecosystem services: challenges and opportunities. A global assessment. Dordrecht, Imprint: Springer, 2013: 175-251.

[6] UCD Urban Institute Ireland. Green City Guidelines: advice for the protection and enhancement of biodiversity in medium to high-density urban developments[R]. 2008.

[7] 沈清基. 城市生态环境: 原理、方法与优化 [M]. 中国建筑工业出版社, 2011: 235.

[8] FORMAN R T T. Urban ecology: science of cities[M]. New York: Cambridge University Press, 2013: 220-223, 241.

[9] DOUGLAS I, JAMES P, Urban ecology: an introduction[M]. Routledge, 2014: 222-228, 241-242.

[10] LUNIAK M. Synurbization-adaptation of animal wildlife to urban development $[\mathrm{C}] / /$ SHAW W W, et al, eds. Proceedings 4th International Urban Wildlife Symposium. 2004: 50-55.

[11] FRANCIS A R, CHADWICK A M. What makes a species synurbic?[J]. Applied Geography, 2012, 32: 514-521.

[12] TOMIAŁOJC L. Human initiation of synurbic populations of waterfowl, raptors, pigeons and cage birds[M] // MURGUI E, HEDBLOM M, eds. Ecology and conservation of birds in urban environments. Springer
International Publishing, 2017: 271-286.

[13] ŁOPUCKI R, MROZ I, BERLIŃSKI L, et al. Effects of urbanization on small-mammal communities and the population structure of synurbic species: an example of a medium-sized city[J]. Canadian Journal of Zoology, 2013, 91(8): 554-561.

[14] 王彦平, 陈水华, 丁平. 杭州城市行道树带的繁殖鸟类及其鸟巢分布 [J]. 动物学研究, 2003, 24(4): 259-264.

[15] MIKULA P, HROMADA M, ALBRECHT T, et al. Nest site selection and breeding success in three turdus thrush species coexisting in an urban environment[]]. Acta Ornithologica, 2014, 49(1): 83-92.

[16] RACEY G D, EULER D L. Small mammal and habitat response to shoreline cottage development in central Ontario, Canada[J]. Canadian Journal of Zoology, 1982, 60(60): 865-880.

[17] BLAIR R B. Land use and avian species diversity along an urban gradient[J]. Ecological Applications, 1996, 6(2): 506-519.

[18] BLAIR R B, LAUNER A E. Butterfly diversity and human land use: species assemblages along an urban gradient[J]. Biological Conservation, 1997, 80: 113-125.

[19] BLAIR R B. Birds and butterflies along an urban gradient: surrogate taxa for addressing biodiversity?[J]. Ecological Applications, 1999, 9(1): 164-170.

[20] BLAIR R B. Birds and butterflies along urban gradients in two ecoregions of the U.S.[M] // LOCKWOOD J L, MCKINNEY M, eds. Biotic homogenization. Norwell (MA): Kluwer, 2011: 33-56.

[21] DENYS C, SCHMIDT H. Insect communities on experimental mugwort plots along an urban gradient[J]. Oecologia, 1998, 113: 114-116.

[22] GERMAINE S S, WAKELING B F. Lizard species distributors and habitat occupation along an urban gradient in Tucson, Arizona, USA[J]. Biological Conservation, 2001, 97(2): 229-237.

[23] MAESTAS J D, KNIGHT R L, GILGERT W C. Biodiversity across a rural land-use gradient[J]. Conservation Biology, 2003, 17(17): 1425-1434.

[24] CROOKS K R, SUAREZ A V, BOLGER D T. Avian assemblages along a gradient of urbanization in a highly fragmented landscape[J]. Biological Conservation, 2004, 115(3): 451-462.

[25] 毛齐正, 马克明, 邬建国, 等。城市生物多样性分布格局研究进展 [J]. 生态学报, 2013, 33(4): 1051-1064.

[26] 颜文涛, 萧敬豪, 胡海, 等. 城市空间结构的环境绩效: 进展与思考 [J]. 城市规划学刊, 2012(2): 50-59.

[27] 林宪德.城乡生态 [M]. 修正二版.台北: 詹氏书局, 2001: 23.

[28] KATHRYN F. Assessing effects of agriculture on terrestrial wildlife: developing a hierarchical approach for the US EPA[J]. Landscape and Urban Planning, 1995, 31(1-3): 99-115.

[29] ALBERTI M, BOOTH D, HILL K, et al. The impact of urban patterns on aquatic ecosystems: an empirical analysis in Puget lowland sub-basins[J]. Landscape and Urban Planning, 2007, 80(4): 345-361.

[30] TRATALOS J, FULLER R A, WARREN P H, et al. Urban form, biodiversity potential and ecosystem services[J]. Landscape and Urban Planning, 2007(83): 308-317.

[31] REIS E, LÓPEZ-IBORRA G M, PINHEIRO R T. Changes in bird species richness through different levels of urbanization: implications for biodiversity conservation and garden design in Central Brazil[J]. Landscape and Urban Planning, 2012(107): 31-42.

[32] 谢世林, 逯非, 曹垒, 等. 北京城区公园景观格局对夏季鸟类群落的影 响 [J]. 景观设计学, 2016(3): 10-21.

[33] JOHNSTON J, NEWTON J. Building green, London ecology unit[R]. 1993.

[34] LEE P F, DING T S, HSU F H, et al. Breeding bird species richness in Taiwan: distribution on gradients of elevation, primary productivity and urbanization[J]. Journal of Biogeography, 2004, 31: 307-314.

[35] PARKER S T, NILON H C. Urban landscape characteristic correlated with the synurbanzation of wildlife[J]. Landscape and Urban Planning, 2012, 106: 316-325.

[36] 葛振鸣, 王天厚, 施文或, 等。环境因子对上海城市园林春季鸟类群落 
结构特征的影响 [J]. 动物学研究, 2005, 26(1): 17-24.

[37] 肖琨。绵阳城市园林中不同类型绿地与昆虫多样性关系的研究 [J]. 现 代园艺, 2005(10): 10, 11.

[38] 晏华, 袁兴中, 刘文萍, 等。城市化对蝴蝶多样性的影响：以重庆市为 例 [J]. 生物多样性, 2006, 14(3): 216-222.

[39] BURGHARDT T K, TALLAMY W D, SHERIVER W G. Impact of native plants on bird and butterfly biodiversity in suburban landscapes[J]. Conservation Biology, 2009, 23(1): 219-224.

[40] VAN HEEZIK Y, SMYTH A, MATHIEU R. Diversity of native and exotic birds across an urban gradient in a New Zealand city[J]. Landscape and Urban Planning, 2008, 87: 223-232.

[41] ORTEGA-ALVAREZA R, MACGREGOR-FORS I. Living in the big city: effects of urban land-use on bird community structure, diversity, and composition[J]. Landscape and Urban Planning, 2009, 90(3-4): 189-195.

[42] 吴建国, 吕佳佳.土地利用变化对生物多样性的影响 [J]. 生态环境, 2008, 17(3): 1276-1281.

[43] GLISTRA D J, DEVAULT T L, DEWOODY J A, et al. A review of mitigation measures for reducing wildlife mortality on roadways[J]. Landscape and Urban Planning, 2009, 91(1): 1-7.
[44] 王版, 阮俊杰, 沙晨燕, 等. 人类活动对上海市生物多样性空间格局的 影响 [J]. 生态环境学报, 2012, 2(1): 279-285.

[45] 胡忠军, 于长青, 徐宏发, 等. 道路对陆栖野生动物的生态学影响 [J]. 生态学杂志, 2005, 24(4): 433-437.

[46] ALBERTI M, MARZLUFF J M. Ecological resilience in urban ecosystems: linking urban patterns to human and ecological functions[J]. Urban Ecosystems, 2004(7): 241-265

[47] MILTNER R J, WHITE D, YODER C. The biotic integrity of streams in urban and suburbanizing landscapes[J]. Landscape and Urban Planning, 2004, 69(1): 87-100

[48] JASON J, CHARLES M F. The effects of light characteristics on avian mortality at lighthouses[J]. Journal of Avian Biology, 2003, 34: 328-333.

[49] 李俊生, 高吉喜, 张晓岚, 等.城市化对生物多样性的影响研究综述 [J]. 生态学杂志, 2005, 24(8): 953-957.

[50] UN-Habitat, et al. Cities and biodiversity outlook: action and policy [R]. Nairobi: UN-Habitat, 2012.

(本文编辑：王枫)

\section{$>>>$ 译者随笔}

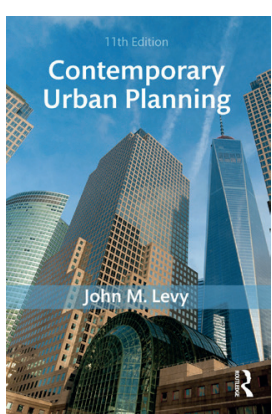

\section{城市规划要讲政治}

叶齐茂

笔者正在翻译美国很多大学使用至今的一本教科书, 《当代城市规划》(第十一版) (Contemporary Urban Planning, 2017)。第一版是 1988 年出版的, 现已经被翻译成四种文字。 2003 年, 人大出版社翻译出版了本书的第五版。对照来看, 第十一版增加了很多新素材、新问题、新争议, 更准确地反 映了当前美国规划界对新世纪城市问题的新视角、新认识、 新观念、新选择和新方法。

不过, 这本城市规划概论初心不改, 从第一版至第十一 版, 一以贯之地给学生灌输一个基本观点, 即当代城市规划 是非常讲政治的, 当代城市规划从来都摆脱不掉政治漩涡, 当代城市规划师在分配土地、空间、资源、环境和利益的活 动中不可能居于中立地位, 总会让一些人有所得, 让一些人
有所失, 因此, 认真分析思考谁是城市规划决策的赢家和输 家至关重要。

《当代城市规划》(第十一版) 给我们讲述的是一个城市 规划师如何选择政治站位的故事。看看美国人如何在做出这 种转变, 看看现在正在影响城市规划的历史、经济、政治、 法律、意识形态和环境因素, 看看各种利益集团如何在那里 围绕土地空间、再城市化、经济适用房、老年人的特殊住房、 新的公共交通开发、绿色建筑的技术和标准、环境和能源政 策、抵御严重自然灾害等问题而展开较量, 看看规划师们如 何在面对这些问题时选择他们的政治站位。

城市规划技术已经相对成熟了, 关键是如何用好它。用 好它的一个关键就是要有一个正确的政治站位。发展是以人 民为中心的, 城市规划也是以不断满足人民日益增长的美好 生活需要为使命的。因此, 在中国争取做一个人民的“规儿 子”是有政治基础的, 当然, 也有迫于权势做 “龟儿子” 的 各种压力。这样, 我们需要科学地掌握城市规划的政治意义, 强化城市规划的政治意识, 增强平衡社会各方利益的政治本 领, 通过解决不平衡不充分问题, 更好满足人民日益增长的 美好生活需要, 赢得群众, 赢得时代。

兼听则明。《当代城市规划》(第十一版) 或多或少可以 给我们带来一些启迪, 至少让我们知道, 城市规划讲的政治 不是“空头政治”, 而是再具体不过的政治实践活动了。UP 